\title{
Shared use of mineral supplement in extensive farming and its potential for infection transmission at the wildlife-livestock interface
}

\author{
Jordi Martinez-Guijosa ${ }^{1}$, Adrián López-Alonso ${ }^{1}$, Christian Gortazar ${ }^{1}$, Pelayo Acevedo ${ }^{1}$, \\ Maria Torres ${ }^{2}$, and Joaquín Vicente ${ }^{1}$ \\ ${ }^{1}$ Instituto de Investigacion en Recursos Cinegeticos \\ ${ }^{2}$ Universidad de Sevilla
}

October 1, 2020

\begin{abstract}
Recently, the survival of Mycobacterium bovis on livestock mineral blocks has been confirmed, but little is known about its implication in the transmission of animal tuberculosis (TB) under field conditions. The objective of this study was to describe the shared use of mineral supplements in four extensive beef cattle farms from a high TB prevalence area in South Central Spain, to identify the main factors explaining their use, and characterize its potential role for the transmission of Mycobacterium tuberculosis complex (MTC). This is relevant to design control measures at the wildlife-livestock interface. Animal activity was monitored by camera-trapping at 12 mineral supplementation points during spring and fall. Additionally, swabs were periodically taken from the mineral substrates and analyzed by PCR searching for MTC DNA. Cattle, pig, goat, sheep, wild boar and red deer were all recorded licking on mineral supplementation points. Livestock species were the main users and presented a diurnal use pattern. Wild ungulates presented a nocturnal-crepuscular use pattern, with scarce overlapping with livestock. Wild boar presence was positively related to cattle presence at mineral supplementation points, whereas red deer presence was higher in supplemental points closer to forested areas, mostly in absence of cattle. We recorded 266 indirect wildlife-livestock interactions (i.e. two consecutive visits that occurred within $78 \mathrm{~h}$ ), all of them derived from 21 unique wildlife visits. All the analyzed swabs resulted negative to MTC DNA. Comparing to other environmental sources of MTC in our study area, mainly water ponds, this research evidenced that mineral blocks are less attractive to wildlife. However, the potential for interspecific transmission of MTC or other pathogens cannot be discarded. The risk for interaction at mineral supplementation points and further transmission can be prevented by implementing specific measures in the context of integral biosecurity plans at the wildlife-livestock interface, which are proposed.
\end{abstract}

\section{Hosted file}

Manuscript.pdf available at https://authorea.com/users/363685/articles/484369-shared-use-ofmineral-supplement-in-extensive-farming-and-its-potential-for-infection-transmission-atthe-wildlife-livestock-interface 


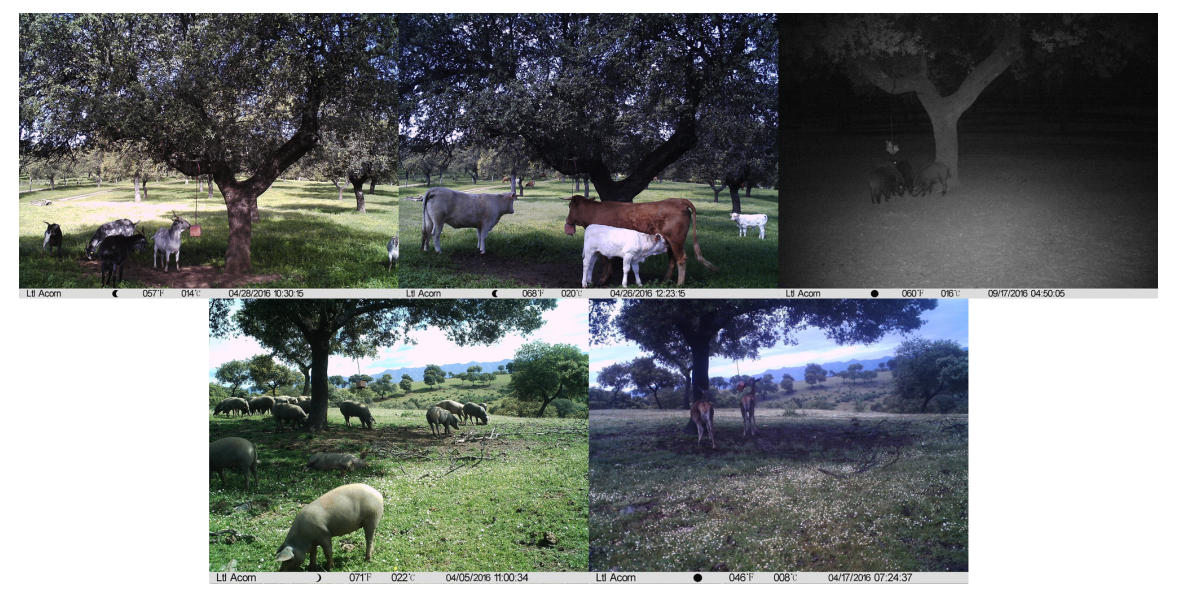

